\title{
INFÂNCIA, LITERATURA E ARTE: \\ UMA ENTREVISTA COM A PROFESSORA ROSANA KOHL BINES (PUC-Rio)
}

A Revista Escrita pediu para a professora Rosana Kohl Bines, do programa de pósgraduação em Literatura, Cultura e Contemporaneidade da PUC-Rio, responder a cinco perguntas por e-mail. As questões foram elaboradas pelo corpo editorial do presente número e visavam procurar interseções entre o campo de estudo da professora e algumas indagações suscitadas pelo tema desta edição. Agradecemos mais uma vez a disponibilidade e a participação da professora.

Um de seus projetos de pesquisa observa o jogo como língua franca da infância e explora os seus modos de ativação e ressurgência em práticas literárias e artísticas que envolvem o brincar como dispositivos de criação. Você pretende expandir esta pesquisa para compreender tal perspectiva no cenário de um campo de refugiados?

Sim, realizamos recentemente uma missão de pesquisa à cidade de Boa Vista, Roraima, onde encontram-se abrigados cerca de 7.000 venezuelanos em situação de refúgio. A pesquisa se insere no âmbito de um projeto interdisciplinar mais amplo, conduzido pela Cátedra Sérgio Vieira de Melo (PUC-Rio/ACNUR), que se dedica a observar a presença e a circulação de populações refugiadas e solicitantes de refúgio de origem venezuelana no Brasil. Em Boa Vista, em fevereiro de 2019, estivemos presentes nos abrigos São Vicente e Jardim Floresta, buscando observar, registrar e descrever os modos como as crianças e jovens abrigados ressignificam práticas lúdicas em cenários de escassez e confinamento. Engajamo-nos em diferentes situações de observação-participante. Fizemos entrevistas qualitativas com as crianças, jovens e educadores locais; criamos situações de convivência lúdica em sessões de contação de histórias, em que circularam repertórios brasileiros e venezuelanos, lembrados pelas crianças abrigadas; fotografamos e filmamos momentos de deriva lúdica das crianças nos espaços dos abrigos. Buscamos ser diligentes com os movimentos de vida que as crianças encenam ao brincar, ao registrar o que ali se faz e se inventa, em contextos de adversidade. Reconhecer as vidas ali vivas e vividas e tomar ciência do que ali se constrói, como escreve a crítica francesa Marielle Macé, no contexto dos migrantes na França. A pesquisa, ainda em fase inicial, envolverá novas viagens à Boa Vista, Roraima. Nesta primeira entrada em campo, apoiada pela Vice-Reitoria de Desenvolvimento da PUC-Rio, contei com a parceria inestimável das 
minhas colegas Liana Biar (Professora do Departamento de Letras, PUC-Rio) e Mariana Braga (Mestranda do Instituto de Relações Internacionais, PUC-Rio).

\section{Em se tratando de crianças refugiadas, em sua opinião, como essas crianças experimentam a arte de brincar? E que criações advém dessa experiência?}

Pelo que pudemos observar em nossa curta estadia nos dois abrigos visitados, as crianças reinventam com quase nada situações de jogo. Desprovidas de brinquedos manufaturados, quase todos deixados pra trás na Venezuela ou vendidos pela família em algum momento para ajudar a financiar a travessia até o Brasil e garantir assim alguma reserva para recomeçar a vida no novo país, as crianças fazem o ambiente inóspito dos abrigos trabalhar a favor de suas reinvenções. Com as britas pontiagudas que cobrem o chão dos abrigos, por exemplo, produzem artefatos inusitados. Criam escorregas improvisados, juntando montes e montes de pedriscos até formar um pequeno morro. Com pedaços de papelão, rasgados das caixas de doação humanitária, deslizam naquela estrutura, que logo depois se desfaz para acolher novas reinvenções. As britas também servem de apoio para a construção de pipas. Pega-se uma brita do chão e uma sacola plástica de supermercado. Puxa-se um fio de dental, até que se tenha uma linha bem comprida. Uma ponta é amarrada na brita e a outra nas alças unidas da sacola. E a pipa está pronta para o voo. As crianças se comprazem também em “desperdiçar” o fio dental - este item de "primeira necessidade," incluído nos kits higiênicos doados nos abrigos em outras criações lúdicas. Constroem uma espécie de "piñata", só que sem as balas ou doces de que as crianças venezuelanas dizem sentir tanta falta, conforme nos relataram, já que as três refeições diárias não incluem sobremesa. Em um fio dental bem longo, amarram-se duas britas, uma em cada extremidade do fio. Joga-se uma das extremidades para o alto de uma árvore, de modo a enganchar o fio em algum galho. A outra extremidade fica na mão da criança, que controla o brinquedo, abaixando e levantando o fio com o pedrisco pendurado. Ela "atiça" as demais crianças que se reúnem embaixo da árvore e tentam pular pra alcançar a pedra que sobe e desce, de acordo com as manobras de quem manuseia o brinquedo. Ganha quem conseguir agarrar a pedra e conquistar assim o direito de ser o próximo a "atiçar" os amigos.

Ao observar alguns dos brinquedos que as crianças fabricam com os materiais dos abrigos, lembramos desta conhecida passagem da obra de Walter Benjamin, que 
vislumbrou nos escombros da paisagem alemã no final dos anos 20, um terreno propício para a ação lúdica e insurgente das crianças:

É que as crianças são especialmente inclinadas a buscarem todo local de trabalho onde a atuação sobre as coisas se processa de maneira visível. Sentem-se irresistivelmente atraídas pelos detritos que se originam da construção [...] Nesses produtos residuais elas reconhecem o rosto que o mundo das coisas volta exatamente para elas, e somente para elas. Neles, estão menos empenhados em reproduzir as obras dos adultos do que em estabelecer entre os mais diferentes materiais, através daquilo que criam em suas brincadeiras, uma relação nova e incoerente. Com isso as crianças formam o seu próprio mundo de coisas, um pequeno mundo inserido no grande. (BENJAMIN, "Canteiro de Obras, Rua de Mão Única)

\section{Vivemos tempos em que a Universidade e o conhecimento científico estão em descrédito. Em sua opinião, de que forma a Universidade pode auxiliar aqueles que perderam e/ou tiveram que deixar seus locais de origem? E como ela pode ajudar na resolução da questão dos campos de refugiados?}

Recentemente, foi realizada na Universidade Federal de Roraima, em Boa Vista, o I Curso Avançado de Direito Internacional dos Refugiados para Professores Universitários. Parte da equipe da Cátedra Sérgio Vieira de Melo participou do curso. O encontro gerou uma série de recomendações, que tocam também no papel das universidades como espaços de reflexão, produção e disseminação de conhecimento, formação de recursos humanos e apoio diversificado às pessoas refugiadas e solicitantes de refúgio no processo de integração local, garantindo acesso a direitos e serviços. Transcrevo abaixo, de forma editada, apenas algumas das recomendações produzidas neste encontro:

- Garantir o diálogo contínuo entre todos os atores envolvidos na proteção, acolhida e integração das pessoas refugiadas e de outros migrantes, incluindo a Academia, com espaços de escuta adequados, e compartilhamento de perspectivas e de experiências.

- Assegurar a capacitação contínua de todos os atores (públicos e privados, nacionais e internacionais) que tenham envolvimento, a qualquer momento, com pessoas refugiadas e outros migrantes, com base em direitos humanos. 
- Criar as condições e realizar estudo robusto e aprofundado sobre a situação atual do sistema de elegibilidade brasileiro, com contribuição da Academia (incluindo as Cátedras Sérgio Viera de Mello) e também de atores que participam do processo, no sentido de fazer um diagnóstico dos problemas existentes e, a partir dele, propor melhorias e políticas públicas na temática.

- Criar e implementar um projeto de capacitação específica nas questões de elegibilidade para formação de pessoal, garantindo-se que a Academia (incluindo as Cátedras Sérgio Viera de Mello) e demais atores que participam da proteção a pessoas refugiadas no Brasil estejam envolvidos em sua preparação e efetivação.

- Divulgar a temática migratória para a sociedade geral, em especial nas Escolas, e com ênfase nos benefícios migratórios e na proteção às pessoas migrantes.

- Incentivar a criação de projetos de extensão universitária na temática migratória.

O lugar onde nascemos e/ou crescemos faz parte de nossas vidas, faz parte de quem somos. Aqueles que precisam, de maneira forçada, deixar tais locais se encontram em uma situação de diversas vulnerabilidades. Não poder voltar para sua terra natal e não ter para onde ir certamente causa traumas. De que forma a literatura pode nos ajudar a compreender as identidades de um refugiado e suas fragmentações?

Para responder, peço ajuda ao artista francês Christian Boltanski, quando, em contexto diverso, diz que "numa guerra não se matam milhares de pessoas. Mata-se alguém que adora espaguete, outro que é gay, outro que tem uma namorada. Uma acumulação de pequenas memórias." Quando a literatura trabalha a favor de memórias e narrativas singulares, colabora para fortalecer um imaginário a contrapelo das imagens massificadas que circulam globalmente acerca dos migrantes, reduzidos a um fluxo estatístico anônimo e indiferenciado. Uma história sempre é contada de determinado ponto de vista, a partir da perspectiva desta ou daquela personagem ou narrador/a, dotando o enredo de paisagens, acontecimentos, sensações, ritmos e entonações que serão sempre contingentes e específicos a cada obra. Ao encenar pequenas vidas migrantes em linguagem, a literatura pode ajudar também a criar dispositivos de atenção para as formas de vida que cada história narrada enuncia. E prestar atenção, no ato de leitura, significa ainda "poder 
ser surpreendido" pelas vidas ali fraseadas, apostando na força das histórias em expor e alterar, mesmo que de forma sutil, as dinâmicas entre quem vê e quem é visto, quem participa ou não da ordem do discurso, quem é considerado ou não como um interlocutor efetivo em determinados grupos e comunidades, para usar os termos de Jacques Rancière. Se pensarmos a cena de leitura como prática intersubjetiva de contato e atravessamento de histórias que nos chegam sempre de outra parte, a experiência literária pode vir a ensejar processos de abertura ao que se toma por estrangeiro, multiplicando e nuançando as formas de ver, perceber e narrar vidas migrantes.

Ouvimos e estudamos o fenômeno da globalização há mais de uma década. A tecnologia nos permite borrar fronteiras físicas, culturais e até linguísticas. Podemos viajar pelo mundo, e a internet nos ajuda a nos comunicarmos com quem quer que seja e em qualquer língua. Nesse sentido, queremos abraçar o mundo; conhecer tudo, se conectar a todos. Falamos de multiculturalismo, panculturalismo, mas quando se trata de integrar apátridas, refugiados em nossa própria cultura, o discurso, ao menos do senso comum, muda. Na contramão das ideias globalizantes e da integração, vivemos tempos de intolerância e ódio. Como você enxerga tal fenômeno?

A primeira observação a fazer diz respeito ao "nós," pressuposto na pergunta. Quem conta como primeira pessoa do plural aqui? Quem são aqueles que podem viajar pelo mundo e se comunicar pela internet em qualquer língua? Quem tem a prerrogativa do passaporte e do livre trânsito entre fronteiras? Quem se assume estar incluído no conjunto de falantes sobre multiculturalismo? Parte do problema está nesta distribuição tácita, silenciosa e assimétrica dos pronomes pessoais e suas respetivas atribuições e valências numa dada comunidade política. Para voltar a Rancière, se a política se ocupa de quem pode tomar parte no comum, ou seja, de quem tem competência para ver, qualidade para dizer e poder para legislar sobre o que é visto e dito, então uma das tarefas que se impõe em contextos de xenofobia e intolerância é a produção de cenas de dissenso, que venham a questionar e redefinir aquilo que é considerado "comum" de uma comunidade. Dito de outra forma, trata-se de intervir também no escopo restritivo do pronome "nós", de modo que aqueles que estão alijados da partilha do comum, como os refugiados e migrantes, mas não apenas estes, possam se fazer visíveis e audíveis, atuando como participantes efetivos na redistribuição de lugares, funções, espaços, tempos e atividades em uma determinada 
comunidade. A literatura e as artes têm um papel expressivo nesses processos, como plataformas de invenção de linguagens e de inscrição sensível de corpos, presenças e palavras, desconsiderados no ordenamento discursivo dominante.

\section{Referências}

BENJAMIN, W. Obras escolhidas II: Rua de Mão Única. (5a ed., R. R. T. Filho \& J. C. M. Barbosa, trads.). São Paulo: Brasiliense, 1995. 